\title{
Legal landmark for community care of former psychiatric patients
}

\author{
Graham Thornicroft, Adina Halpern
}

\begin{abstract}
A recent judgment of the Lands Tribunal has set an important precedent which should decrease the potential for restrictive covenants to thwart the development of the government's care in the community programme. In 1989 a Worthing couple were permitted to convert their own house into a residential care home for former psychiatric patients. Judge B Marder, QC, ruled on 12 January 1993 that the "public interest" outweighed a contractual stipulation that the property should be used only for residential, non-business purposes. This is a radical change in the Lands Tribunal's view of mental illness.
\end{abstract}

In August 1989 the borough of Worthing in West Sussex granted planning permission to Penny and Richard Lloyd to change their own home into a residential care home for 10 former psychiatric patients. Both had relevant experience. For several years $\mathrm{Mr}$ Lloyd had managed a local residential home for elderly people, and Mrs Lloyd, a trained psychiatric nurse, managed a community based 14 bedded NHS inpatient unit for short stay psychiatric patients preparing to return home.

$\mathrm{Mr}$ and Mrs Lloyd were aware of the serious deficiency in Worthing of acute beds and staffed residential places for people with mental health problems. The local Homefield unit had only 38 acute beds, far fewer than the 85 bed minimum recommended by the Royal College of Psychiatrists. ${ }^{1}$ Indeed, in 1992-3 Worthing received less than $85 \%$ of the level of government funding recommended by the government's own capitation calculations. ${ }^{2}$

The Lloyds's proposal, which was supported by one of us (GT) acting as an expert witness, was in keeping with the requirements of the National Health Service and Community Care Act 1990 in seeking to provide one component of a "mixed economy" of local care. It was also consistent with the West Sussex Community Care Plan 1992-1993, which pledges that "people with mental health problems should be enabled to live as independently as possible in the community... [and] should live in ordinary style accommodation with additional support as necessary."

$\mathrm{Mr}$ and Mrs Lloyd decided to bring an action in the Lands Tribunal to pre-empt possible legal action from local objectors. They applied under section 84 of the Law of Property Act 1925 to discharge or vary a covenant imposed in 1935 that restricted their house from being used "for any trade or business whatsoever." They advanced their case on the ground that the restrictive covenant was against the public interest. ${ }^{3}$

Service Measurement

(PRiSM), Institute of

Psychiatry, London

SE5 8AF

Graham Thornicroft, director

MIND, National

Association for Mental

Health, London W1N 4ED

Adina Halpern, legal and

parliamentary officer

Correspondence to:

Dr Thornicroft.

$B M f$ 1993;307:248-50 compensation should the judge agree the modification, as they claimed they would suffer "considerable diminution in the value" of their properties.

\section{Expert witnesses}

Presenting evidence on the use of local buildings, $\mathrm{Mr}$ J P Tupper, a local chartered surveyor appearing for the Lloyds, argued that although the restrictive covenant was intended to prevent non-residential use of the property, in fact the covenant had long been breached by a large home for elderly people in the same road and by other neighbours who seemed to run businesses from their homes. He concluded that the proposed community care home would therefore have no material effect on the surrounding properties.

For the opposers, Mr J C Barrass, also a chartered surveyor, argued that the locality was "a good class residential area" and that the proposed use would "jeopardise the continued future use and demand for such properties as family homes"; in particular, he claimed that "privacy would be seriously eroded." $\mathrm{Mr}$ Barrass estimated a reduced combined property value of $£ 144000$ to the objectors by drawing some comparisons: "in the same way that given a choice most families try, if finances allow, not too live to near to Beecham's factory in East Worthing or too near to the main Worthing sewage disposal works at the eastern end of the sea front because of the odours emitting from both of these establishments."

The medical witness for the opponents, Dr Patrick Carr, an authority on community psychiatric nursing, expressed the view that should the home open, then "the term nuisance might well be relevant in this context, and even the possibility of bizarre and disturbed behaviour." He nevertheless supported the overall direction of government policy and indicated that he was "wedded to the notion of care in the community" but that "the problem about this area is that the general public does not understand mental illness, nor do they, generally speaking, want to know anything about it."

Speaking for the Lloyds, GT presented evidence to show that the proposed use of the house was entirely consistent with national policy on mental health service development, which explicitly requires the continuing replacement of long term hospital treatment by local community based forms of care. ${ }^{4-6} \mathrm{He}$ indicated that a consensus had emerged from research findings that community based psychiatric services are as good or better than the older hospitals on all the measures that have been used. ${ }^{7}$ Indeed, when patients themselves and their families are asked for their preferences they overwhelmingly favour community to hospital care. ${ }^{8}$ He therefore argued that the proposed used was fully consistent with British government policy for people disabled by psychiatric illness and with the guidelines also set out by the World Health Organisation and the National Institute of Mental Health. ${ }^{910}$ In addition, a local consultant psychiatrist, Dr A McPherson; the Worthing mental health services manager, Mr A R Curtis; and the former director of the health advisory service, Dr D H Dick, gave written evidence to support the development of the community care home 


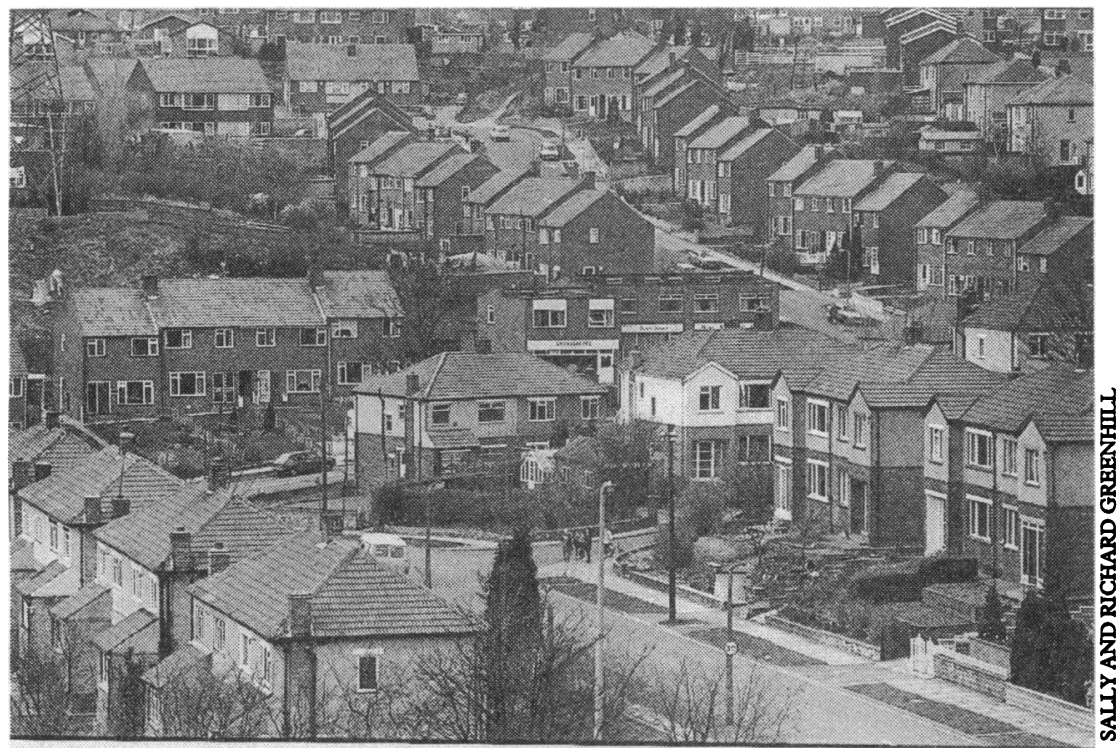

Depending on public need, restrictive covenants preventing ordinary houses being used as residential care homes for former psychiatric inpatients may be discharged or varied under section 84 of the Law of Property Act 1925

and added that the range of services was notably inadequate, especially for continuing care.

\section{The judgment}

The restrictive covenant was modified so as to permit the use of the Lloyds's home as a residential care home for not more than 10 residents, in accordance with the planning permission in force and subject to the registration of the premises under the Registered Homes Act 1984.

The judge decided that compensation was not relevant because the covenant, which it was accepted impeded the use of the property as a community care home, was of no substantial benefit or advantage to the neighbours. This was because the restrictive covenant already permitted a boarding house or school and, "if anything, the use of the subject property as a school is likely to be more injurious in the form of noise, disturbance and accompanying activity" than a community care home.

The judge accepted that his ruling was the first in legal history-other than in two isolated cases to prevent demolitions-where the notion of "public interest" had been invoked to vary the terms of a house covenant. He overruled objections from neighbours and dismissed their claims for compensation, finding their "fears and apprehensions" about the home's future residents "groundless." His conclusion is important: "There is no evidence to suggest that the conduct of the proposed occupiers... would be more or less objectionable or anti-social than if the property were occupied, for example, as a boarding house for ten residents chosen at random from the community at large."

In terms of the strength of the Lloyds's case as a legal precedent it is important to note the relevant facts behind the decision. The judge accepted that the need for community care homes in Worthing was "desperate" and that the property was "in all respects suitable" to be used for that purpose. That the Lloyds were particularly well qualified to run a community care home was also influential.

\section{Legal precedents}

The ruling in Worthing weakens the effect of the 1990 C \& G Homes test case, in which the Court of Appeal found that similar convenants had been breached by the occupation of two houses by dis- charged psychiatric patients. The C \& G Homes case concerned a community care home set up by the secretary of state for health in the guise of Bath Health Authority for people being discharged from a long stay psychiatric hospital." In this case, although Lord Donaldson found that "in many respects the way in which the Secretary of State's houses are being used is quite indistinguishable from the way in which the other houses on the estate are being used," the unanimous decision of the Court of Appeal was that the houses were not being used as private dwelling houses. As a result the use of the homes for these particular residents breached covenants providing that they could be used only for purposes "incidental to the enjoyment of a private dwelling house."

What seems to have persuaded the judges in this decision was that all the residents had a "special" relationship with the hospital, from which in many senses they had not really been discharged. It was therefore "the special nature of their occupation" which made the homes in many ways like a hospital annex rather than private dwelling houses.

The view of the Court of Appeal contrasted with that of the first judge in the case, who concluded that the residents were "very different from an ordinary family unit occupying a private dwelling house." The higher court also reversed the order of the first judge in relation to compensation for the "detriment" he found that neighbours had suffered as a result of these residents having been placed on the estate.

Had the residents been treated less like inpatients the judges in the Court of Appeal may well have held that the homes were being used as private dwellings. For example, if the occupiers had been tenants rather than licensees with no rights to occupy the home. In any case, it is clear that the C \& G Homes case has major ramifications for the setting up of NHS financed and managed community care projects: residents need to be granted clear and secure housing rights.

\section{Implications of the Worthing decision}

The C \& G Homes case emphasises the freedom which the law gives to property owners to restrict the use of private residences in a discriminatory way when they enter into a contract to sell their land, thus enabling segregation and prejudice to continue. The Lloyds's case set a precedent for challenging "old" restrictive covenants to which a buyer is not a party rather than "new" covenants such as those the secretary of state entered into when the health authority bought the two properties concerned in the $C \& G$ Homes case.

As in the C \& G Homes case, the Lloyds's proposed community care home was in a "good class and desirable residential area." The modification of a covenant in these circumstances thus prepares the way for community care homes to be set up in such areas. The case illustrates the "not in my back yard" principle for what it is in the context of rehabilitating people who have been diagnosed as having a mental illness-that is, against the public interest and based on ignorance and groundless prejudice.

The judge's comments about the assumed character and characteristics of the potential occupants and the fears and apprehensions of the local residents may therefore be important in allaying the fears of potential neighbours to a community care home. His comments also indicate a radical change in the attitude of the Lands Tribunal to people with mental health problems. This is important given that the associations between mental illness and criminality are still far from clear. A wide ranging review, which was cited at the hearing, concluded that such links are unproved. ${ }^{12} 1314$

The 1955 decision of the Lands Tribunal in the $\mathrm{Dr}$ 
Barnado's Home case makes chilling reading and indicates how far the tribunal has moved in attitude since then. In that case an application to modify a 1901 covenant prohibiting land from being used as an "asylum for the insane" was turned down because the judge held that "The very act of imposing such a covenant discloses the universal abhorrence felt by ordinary folk for the 'mental case' and while that revulsion may derive from ignorance and be justly stigmatised as prejudice it is no less poignant for being unjustified." He went on to find that "this prejudice aggravated rather than mitigated by the isolation of this [exists] to an extent wide enough to affect the values of adjacent properties and that such effect is aggravated rather than mitigated by the isolation of this rural community." 15

Finally, the Lloyds's case establishes that community care is in the public interest, and because of this the Lands Tribunal will find if difficult to conclude otherwise when it is considering an application to modify a restrictive covenant. Expert evidence will not be necessary to establish this fact. However, it will be interesting to see what will happen in a forum such as the Lands Tribunal if government policy shifts, given that "public interest" and government policy may not be the same thing. Although the Lloyds's case turns on its special facts, it sets an important precedent and should encourage the much needed development of community care housing. We hope that it will discourage future protests and contribute to an understanding of and sensitivity towards people with mental health problems.

\footnotetext{
1 Hirsch S. Psychiatric beds and resources; factors influencing bed use and service planning. London: Royal College of Psychiatrists, 1988.

2 House of Commons official report (Hansard) 1992 July 15;595; $\mathrm{col} 2$.

3 West Sussex County Council. West Sussex community care plan 1992-1993. Chichester: WSCC Social Services Department, 1993.

4 Department of Health. The health of the nation. London: HMSO, 1991.

5 Social Services Committee. Second report from the Social Services Commitzee. Session 1984-85, community care. London: HMSO, 1985.

6 Department of Health and Social Security. DHSS background policy papers. In: Wilkinson G, Freeman H, eds. The provision of mental health services in Britain: the way ahead. London: Royal College of Psychiatrists, 1986.

7 National Health Service and Community Care Act 1990. London: HMSO, 1990.

8 North East Thames Regional Health Authority. Team for the assessment of psychiatric services 1990. Better out than in? London: NETRHA, 1991.

9 World Health Organisation. Implications for the field of mental health of the European targets for attaining health for all. Copenhagen: W/HO, 1991.

10 National Institute of Mental Health. Towards a model for a comprehensive community-based mental health system. Washington, DC: NIMH, 1987.

11 C \& G Homes Limited $v$ Secretary of State for Health [1990] 2 All ER 841.

12 Teplin L. The criminality of the mentally ill: a dangerous misconception. Am F Psychiatry 1985;142:593-9.

13 Lindquist P, Allebeck P. Schizophrenia and crime: a longitudinal follow-up of 644 schizophrenics in Stockholm. Br P Psychiatry 1990;157:345-50.

14 Swanson J, Holzer C, Ganju V, Jono R. Violence and psychiatric disorder in the community-evidence from the epidemiologic catchment area surveys. Hosp Community Psychiatry 1990;41:761-70.

15 Dr Barnado's Homes National Incorporated Associations. Heard by Lands Tribunal. Decision 1955 June 14. (Application LP/102/1954.)

(Accepted 13 May 1993)
}

\title{
Global regulations on diabetics treated with insulin and their operation of commercial motor vehicles
}

\author{
DiaMond Project Group on Social Issues
}

Governments often regulate who may and may not drive vocationally for public safety purposes. Recent arguments, however, imply that employment opportunities may be limited unnecessarily for people with medical impairments. Drivers with diabetes treated with insulin are commonly perceived to pose an increased risk of accidents because of their susceptibility to hypoglycaemia. Much uncertainty, though, surrounds the data on the risks of these drivers. An international survey studied the licensing policies applied to professional lorry drivers with diabetes treated with insulin. Responses from 24 countries indicated that regulations differ considerably; ranging from a complete ban on professional driving to no restrictions at all. Many reasons may explain this difference, including the lack of data on the effects of hypoglycaemia on the incidence of traffic accidents. A proper account of the risks of diabetic drivers is necessary to balance fairly the rights of employment against the risks.

Governments face difficult decisions about occupational safety. On one side, they are encouraged to produce regulations and guidelines that provide optimal protection to the health and vocational capacity of their people. On the other side, overtly restrictive regulations may limit the rights and opportunities of broad segments of the population to earn a living. Striking a balance between the two often depends on the views and perceptions of society. ${ }^{12}$

In the subject of operation of commercial motor vehicles governments often regulate who may and may not drive lorries weighing over $3500 \mathrm{~kg}$. Most commonly drivers are judged by their competence to operate a large vehicle, their physical and medical condition, and their history of accidents. Such stipulations in motor vehicle licensing are designed to exclude high risk drivers ${ }^{3}$ and to protect other road users and society from the burdens and cost of unnecessary injury. The implications of disregarding the public's safety are obvious, as a large lorry lurching out of control at high speed may lead to a catastrophe. The implications of limiting the public's job opportunities, however, may potentially be just as important. Not only is driving a commercial motor vehicle a reasonably highly paid profession across the world but the transportation industry is a major source of employment.

People with insulin dependent diabetes mellitus are currently at the centre of many arguments over risks and rights of employment. The threat of occupational accidents from hypoglycaemia is very real. Hypoglycaemia is capable of occurring in any person using insulin and, in its most severe form, can lead to a sudden loss of consciousness. Many studies, however, suggest that the risk of severe hypoglycaemia may not be the same for every person who takes insulin. Severe hypoglycaemia seems to occur in a minority. ${ }^{48}$ Together with the development of technology which enables people to monitor their own blood glucose concentrations, it would seem that a fair number of people taking insulin may theoretically be able to work with minimal risk.

A debate now underway in America and Europe concerns whether operation of commercial motor vehicles should be restricted or prohibited for all people taking insulin or only those at a high risk of hypoglycaemia. Recent legislation and legal judgments on job discrimination in Canada and the United States have pushed both countries into considering a change from a complete ban to a less restrictive stance. ${ }^{9-12}$ In contrast, the European Community is considering regulations which would recommend a complete ban within each member country. ${ }^{13}$ Because of these changing stances, we undertook an international survey

School of Public Health 